\title{
High-Temperature Overpressure Basin Reservoir and Pressure Prediction Model
}

\author{
Aiqun Liu, Jiaxiong Zhou, Dianyuan Chen, Bentian Ou, Caiwei Fan, Wentuo Li \\ Zhanjiang Branch of CNOOC Ltd., Zhanjiang, China \\ Email: xiaoliliu_1982@126.com
}

Received 25 April 2015; accepted 19 June 2015; published 24 June 2015

Copyright (C) 2015 by authors and Scientific Research Publishing Inc.

This work is licensed under the Creative Commons Attribution International License (CC BY). http://creativecommons.org/licenses/by/4.0/

(c) (i) Open Access

\begin{abstract}
Yinggehai Basin locates in the northern South China Sea. Since the Cainozoic Era, crust has several strong tension: the basin subsides quickly, the deposition is thick, and the crust is thin. In the central basin, formation pressure coefficient is up to 2.1; Yinggehai Basin is a fomous high-temperature overpressure basin. Yinggehai Basin's in-depth, especially high-temperature overpressure stratum has numerous large-scale exploration goals. As a result of high-temperature overpressure basin's perplexing geological conditions and geophysical analysis technical limitations, this field of gas exploration can't be carried out effectively, which affects the process of gas exploration seriously. A pressure prediction model of the high-temperature overpressure basin in different structural positions is summed up by pressure forecast pattern research in recent years, which can be applied to target wells pre-drilling pressure prediction and post drilling pressure analysis of Yinggehai Basin. The model has small erroneous and high rate of accuracy. The Yinggehai Basin A well drilling is successful in 2010, and gas is discovered in high-temperature overpressure stratum, which proved that reservoir can be found in high-temperature overpressure stratum. It is a great theoretical breakthrough of reservoir knowledge.
\end{abstract}

\section{Keywords}

High-Temperature Overpressure, Yinggehai Basin, Pressure Prediction Model, Reservoir Theory

\section{Introduction}

The Yinggehai Basin is a quick settlement of Cenozoic sedimentary basin; abnormal high temperature high pressure is one of its important characteristics [1]-[3]. Advanced rapid settlement and rapid deposition formed a thick undercompacted mudstone, which produced abnormal high pressure. To keep abnormal high pressure, the stable subsidence and weak tectonic activity are necessary. The overpressure interface of basin central diapir 
zone is shallow, but different diapir structure still have different overpressure interface. Overpressure top interface is generally $1500-2500 \mathrm{~nm}$; while the non-diapir zone overpressure interface of the southern part and edges of the basin is generally deep, and overpressure interface was significantly affected by stratum, lithology and basin boundary faults (Figure 1). According to literature report, two third of sedimentary basins in the world have developed different degrees of overpressure, among which about 160 sedimentary basins' oil and gas distribution has a close genetic relationship with overpressure body. The large-scale and medium gas fields have been found by foreign petroleum company, which indicated that overpressure has close relationship with oil-gas generation, migration, reservoir and distribution. In recent twenty years, with the development of oil and gas exploration research, especially of the overpressure and its growth mechanism, the relationship of overpressure and hydrocarbon reservoir, overpressure has been paid more attention in oil-gas exploration and development.

\section{The Existing Problems of Yinggehai Basin Because of the Existence of High Temperature and High Pressure}

The Yinggehai Basin is a quick settlement of Cenozoic sedimentary basin, abnormal high temperature high pressure is one of its important characteristics. Advanced rapid settlement and rapid deposition formed a thick undercompacted mudstone, which produced abnormal high pressure. To keep abnormal high pressure, the stable subsidence and weak tectonic activity is necessary. The overpressure interface of basin central diapir zone is shallow, but different diapir structure still have different overpressure interface. Overpressure top interface is generally 1500 - $2500 \mathrm{~m}$; while the non-diapir zone overpressure interface of the southern part and edges of the basin is generally deep, and overpressure interface was significantly affected by stratum, lithology and basin boundary faults (Figure 1). According to literature report, two third of sedimentary basins in the world have developed different degrees of overpressure, among which about 160 sedimentary basins' oil and gas distribution has a close genetic relationship with overpressure body. The large-scale and medium gas fields have been found by foreign petroleum company, which indicated that overpressure has close relationship with oil-gas generation, migration, reservoir and distribution. In recent twenty years, with the development of oil and gas exploration research, especially of the overpressure and its growth mechanism, the relationship of overpressure and hydrocarbon reservoir, overpressure has been paid more attention in oil-gas exploration and development.

\subsection{The Problems of Undrilled Well's Pre-Drilling Pressure Prediction}

Because of the existence of high temperature and high pressure of Yinggehai Basin, drilling safety must be paid more attention in the process of drilling. Pressure prediction before drilling is the foundation to design the drilling well structure, taking undrilling B well of Yinggehai Basin as an example, the result of pressure prediction

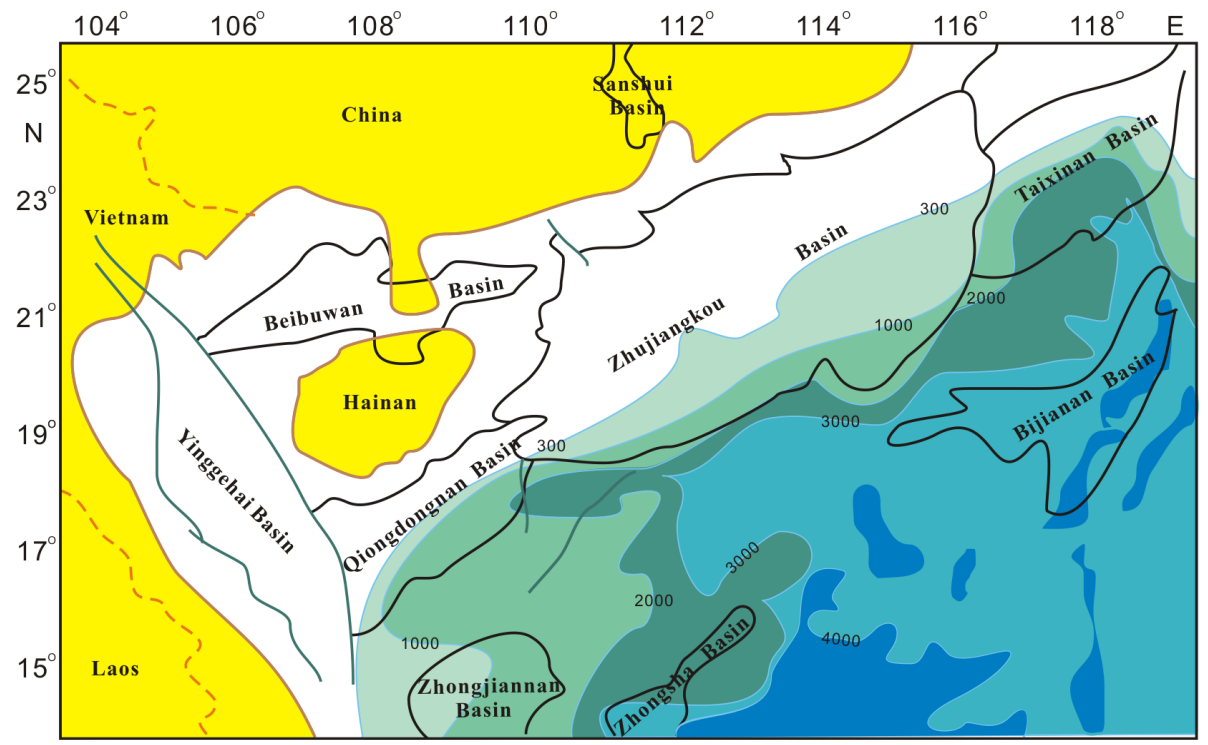

Figure 1. Design of pre-drilling pressure prediction and wellbore structure. 
(Figure 2) can be instructions of the location of casing and mud weight whiling drilling [4]-[7]. However, as Yinggehai Basin hasn't been explored deeply, with few drills, which have difficulties in judging the pressure origin because of the existence of diapirs, so it is difficult to predict pre-drilling pressure of high-temperature and high pressure basin [8] [9].

At present the formation velocity is used as the main parameters of pre-drilling formation pressure prediction and post-drilled pressure calculation, Interval velocity increases with depth in normal compaction stratum, which is smaller than normal value in abnormal high-pressure stratum (usually referring to the undercompaction causes of formation), therefore abnormally high-pressure stratum can be determined and detected by velocity anomaly changes. Velocity can be obtained not only from post-drilled logging, but also from pre-drilling seismic stacking velocity spectrum. After years of research in Yinggehai Basin's pressure prediction and calculation method, combining with the data of drilled well, "differential method" is regarded as a suitable method to calculate the pressure of Yinggehai Basin. This method is proposed by P. Bellotti et al. of Italian General Petroleum Company, which is a empirical formula method (Figure 2). First of all, defining velocity anomaly:

$$
\Delta V=V_{i}-V_{n}
$$

In the fomula $V_{i}$ : calculation velocity; $V_{n}$ : tendency velocity. The standard to identify abnormal pressure zone by velocity anomaly is: $\Delta V=0$ normal compaction stratum; $\Delta V<0$ abnormally high-pressure stratum, the regional empirical formula $P=f(\Delta V)$ should be established to calculate pore pressure quantitatively. This method does not need to calculate the overburden pressure, which can reduce error and some uncontrolled factors. For differential method, the most important and difficult is to determine the corresponding pressure prediction model of velocity difference and pressure coefficient.

\subsection{The Difficulties in Knowing Reservoir}

Massive research in domestic and foreign indicated that oil and gas gathered within pressure transition zone which above the overpressure top, pressure coefficient is $1.2-1.5$. The stratum can rarely produce oil and gas when the pressure coefficient surpasses 1.8, most strata will rupture when surpassing this pressure coefficient, especially in clastic rock areas, overlying strata will be fractured, which can cause oil and gas dissipation when formation pressure reaching $75 \%$ to $95 \%$ of the overlying lithostatic pressure. So caprock conditions are strictly requested to form strong overpressure oil and gas reservoir.

The pressure coefficient of Kela-2Giant Gas Field in Kuche Depression, Tarim Basin can reach 2.0, due to the well developed gypsum cover. Viking Graben of Beihai Basin and overpressure oil and gas reservoir (such as Venture Field) of Nova Scotia continental shelf in the east of Canada formed in Jurassic shale overpressure sediment group more than $4000 \mathrm{~m}$ deep, the shale is not only high-quality hydrocarbon source rock, but also good cover.

To solve the problem of deep high-temperature and high pressure gas reservoir of Yinggehai Basin, the pro-
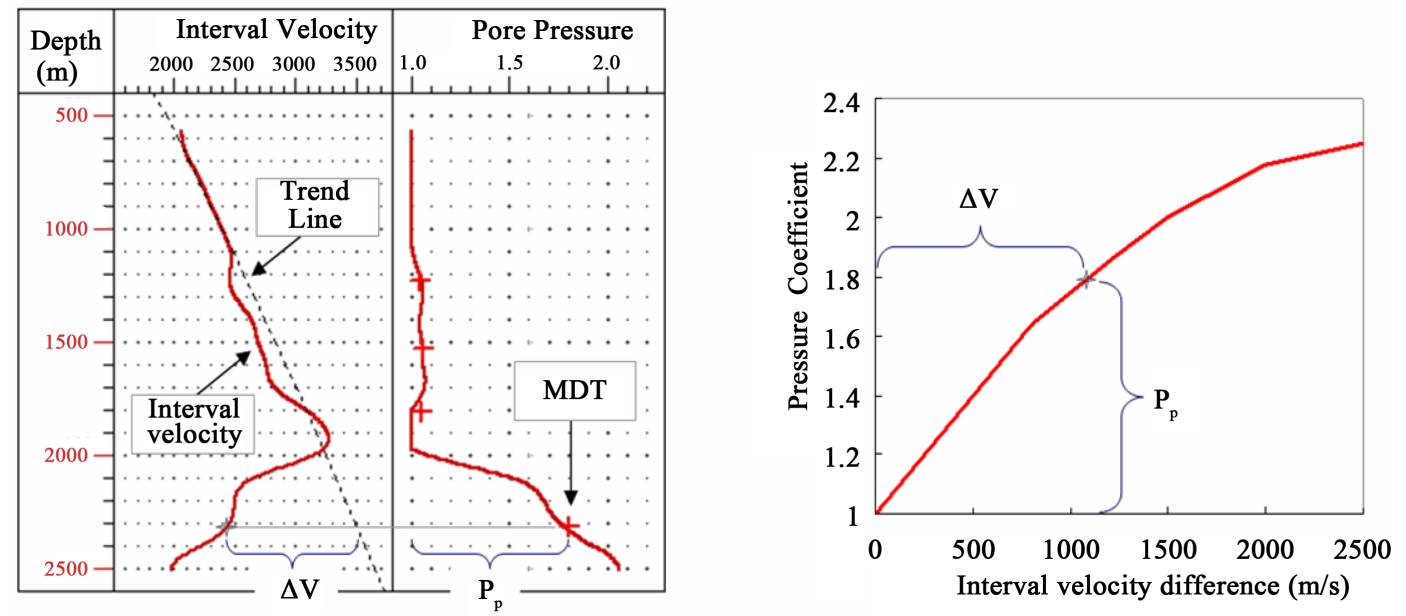

Figure 2. Schematic diagram of the pressure difference method calculations. 
blem that if gas can massively form free gas reservoir on the high-temperature overpressure condition of middeep temperature higher than $140^{\circ} \mathrm{C}$, pressure coefficient bigger than 1.8 must be solved. Some experts think that reservoir can't be formed in overpressure strata. If the pressure coefficient surpasses 1.5, reservoir will produce elastic-plastic deformation, primary pores and cracks will be closed and the formation permeability will greatly deduce. In addition, the overpressure layer pressure gradient is too small, gas migration energy have been significantly weakened, so gas can't form reservoir. More than 10 high-pressure drilled well of Qiongdongnan Basin which pressure coefficient surpasses 1.8 didn't form reservoir, therefore, this view was supported by many people in gas exploration of Yinggehai Basin. There are two reasons that cause deep abnormal highpressure of Yinggehai Basin. First of all, deep mudstone can generate high pressure, and then, dapiric can conduct deep basin high pressure. Although overpressure formation depth that different diapiric zone formed is not the same, it is shallower than other basins. Drilling shows that formation pressure coefficient can reach 1.5 near $2000 \mathrm{~m}$, and formation pressure coefficient usually surpasses 1.8 under $3000 \mathrm{~m}$, which is overpressure (Figure 3). Furthermore, deep strata lies in later times (middle-late Miocene), which have developed large sets of neritic facies mudstone clastic rock formation. This type of formation played a good role of sealing in diapir shallow layer of normal temperature and pressure gas field, but under deep high-temperature and high-pressure environment, especially in large-scale diapiric anticline zones, diapiric activity not only created good channel to migrate oil and gas, but also transformed deep large anticline cover. In such an environment, it is a doubtful that if the formation have sufficient sealing ability, and resulting in concerns that if gas reservoir can be formed under deep high-temperature and overpressure condition.

\section{Pressure Prediction Model of Yinggehai Basin}

During the gas exploration of Yinggehai Basin, it has been found that overpressure formation appeared due to the rapid basin subsidence and Hydrocarbon generation of organic matter. The overpressure mudstone is in the uncompacted state, with high porosity, which shows the parameters deviate from normal trends in logging data, that is: small density, large acoustic time etc. In addition, seismic velocity is small, so pressure distribution characteristics can be determined according to the parameter variation. The Yinggehai Basin lies in abnormal pressure zone, wave impedance, speed and density decreases with the increase of depth, local has strong reversal phenomenon. For the pressure prediction difference method that Yinggehai Basin has currently taken, the most

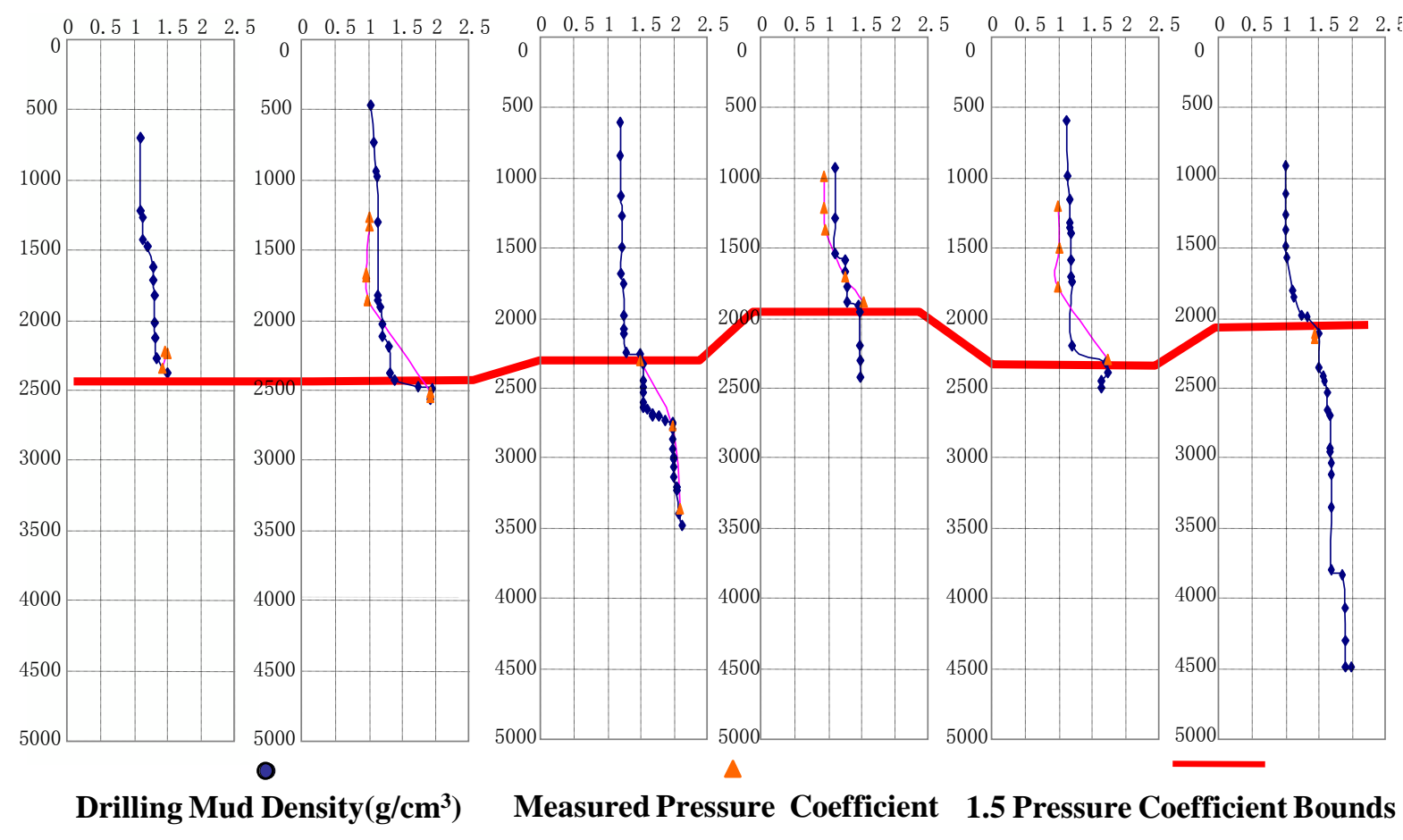

Figure 3. Diapiric zone of Yinggehai Basin overpressure limit well pressure contrast profiles. 
important and difficult is to determine the corresponding pressure prediction model of velocity difference and pressure coefficient. After years of exploration and drilling, combined with mud data, pressure and test data of drilled well, the author has summed up pressure prediction model in different structural positions of the basin (Figure 4) and has formed the basic pressure prediction model of Yinggehai Basin.

Figure 4(a) started with tectonic framework of Yinggehai Basin, summed up the pressure prediction model in the center and the edge of the basin. For the same velocity difference, the pressure coefficient in the center of the basin is higher than that of the edge of the basin, because the center of basin locates in rapid deposition zone of sediments, the mudstone is in the uncompacted state, while the edge of the basin locates in passing by region of sediments, the strata in the edge of basin is older than that of the center of basin in the same depth, Formation Velocity is much higher, so pressure coefficient in the center of basin is higher than that of the edge of basin.

Figure 4(b) started single gas-bearing structure and summed up the pressure prediction models of different zones, including Dongfang Diapir and Ledong Diapir of Yinggehai Basin, Yingbei-lingao and Yingdong-xiepo, it is indicated that the trend of velocity difference and pressure coefficient is consistent in Yingbei-lingao and Yingdong-xiepo, and there is not much difference between the value, while the trend of velocity difference and pressure coefficient is consistent in Dongfang Diapir and Ledong Diapir, but there is much difference between the value. When velocity difference is less than $1200 \mathrm{~m} / \mathrm{s}$, the relationship of pressure coefficient demonstrates Dongfang Diapir > Ledong Diapir > Yingbei-lingao and Yingdong-xiepo; when velocity difference is more than $1200 \mathrm{~m} / \mathrm{s}$, the relationship of pressure coefficient turns into Dongfang Diapir > Yingbei-lingao and Yingdong-xiepo > Ledong Diapir. It is thought the reason this relationship appears is that: 1) In terms of structural location, Dongfang Diapir and Ledong Diapir are both in the center of basin, while Yingbei-lingao and Yingdong-xiepo are in the edge of basin, so trend of diapir and basin margin is different, the pressure coefficient of diapir is higher than that of basin margin when velocity difference is slight; 2) Although Dongfang and Ledong belong to diapir, but the diapir scale and the diapir activity period is not very consistent, it is found out that diapir activity is characterized by episodic structure, it is likely that Dongfang Diapir is in pressure savings period of episodic activity, the overburden has not been broken, pressure has not been released, while Ledong Diapir may end pressure discharge period recently, pressure has been released, therefore, when velocity difference is larger, pressure coefficient of Ledong Diapir is smaller than that of Yingbei-lingao and Yingdong-xiepo which locates in the edge of basin; 3) Pressure has a certain role in the transmission, Yingbei-lingao and Yingdongxiepo locates in the edge of basin, deep formation pressure is not very high, besides, the better relief channel turns to have coarse sediment, therefore, deep formation pressure is not transmitted to the shallow layer, while Ledong Diapir may just end discharge period, which fractures and faults are in the closed state, so it is difficult to transmit deep formation pressure to the shallow layer. Therefore, the overall trend of velocity difference and pressure coefficient in the two regions is consistent with that in the center and edge of the basin. The pressure coefficient of Dongfang Diapir significantly deviates from its normal trend, the reason is that deep formation pressure is delivered to the shallow formation through faults and fissures to form stratum pressure.

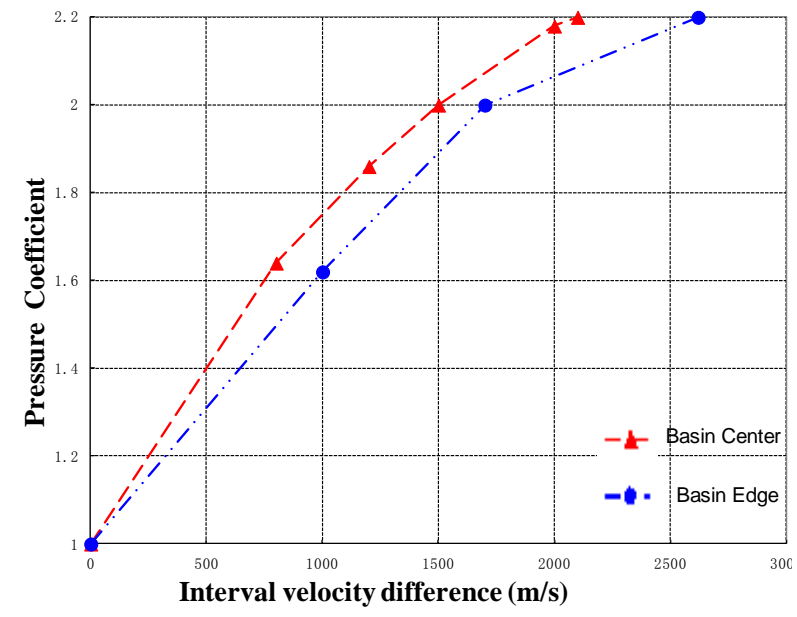

(a)

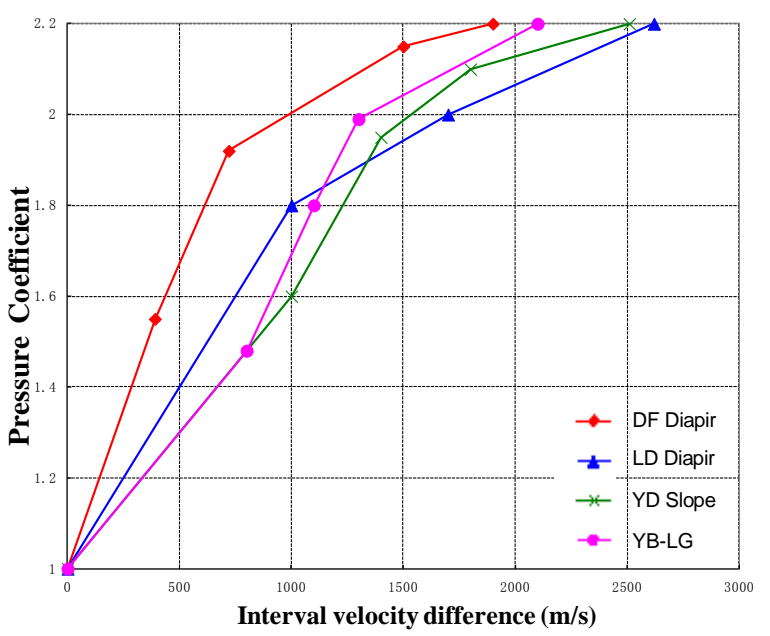

(b)

Figure 4. Pressure prediction speed differential-pressure coefficient model of Yinggehai Basin. 


\section{Breakthrough of Recognition of High-Temperature and High-Pressure Reservoir Pattern}

During the gas exploration of Yinggehai Basin, with the shallow exploration at room temperature atmospheric pressure deepening day by day, the gas exploration potential and reservoir of deep strata has been paid more attention byacademic and geological circles, as a hot topic, high-emperature and high-pressure reservoir has aroused strong repercussions for many times. As a late start in the deep gas exploration, lack of success can learned from, the reservoir theory and drilling at high-emperature and high-pressure is going on slowly.

One of focal questions the geological experts and explorers have paid close attention to is that if mudstone caprock can cover abnormal high-pressure scales of gas. This depends on the quality of deep mudstone caprock and the sealing ability. DFC Well and DFD Well are two exploration well in deep, which are within diapiric anticline structure. Although the Huangliu Formation demonstrated a large set of a shallow mudstone, the analysis shows the mudstone is not pure, mostly silty mudstone, so the cover turns to be low quality. The two wells proved that there are reasons to be concerned about low quality of deep mudstone cover.

After the failure of LDA Well (A well in LeDong zone) drilling, deep exploration in diapir belt of Yinggehai Basin has come to a standstill. After constantly study and discussion, in early 2009, LOTUSA Well was drilled on another diapiric structure in the west of Dongfang 1-1, during the drilling, fine sandstone reservoir was found in Huangliu Group and Meishan Group, and gas reservoir was discovered, MDT (Mouldar Formation Dynamics Test) and DST (Drilling Stem Test) data showed that the pressure coefficient of 1.98, which belongs to strong overpressure stratum, and its pressure of the underlying strata was much higher, which pressure coefficient surpassed 2.0. Although the majority of $\mathrm{CO}_{2}$, but it is proved that the strong overpressure sealing box can form free gas reservoirs. As a revelation, deep reservoir of Dongfang 1-1 was studied again, DFB Well (B well in Dongfang zone) was drilled in the northeast wing of the structure for theshallow beach sandstone reservoir in Huangliu Group of Hainan Source. This well also reached gas, the MiniDST test turned to be successful, and gas samples are obtained, mostly hydrocarbon gas, and formation pressure coefficient showed to be 1.92. This well illustrated that hydrocarbon gas of high quality can accumulate in deep strong overpressure stratum of diapir. All the facts prove that reservoir can be formed not only in pressure transition zone, normal pressure zone at the top of overpressured compartment, but also in deep overpressure sealing box in diapir. The existence of free hydrocarbon gas in overpressure zone, which should the confidence to explore deep diapir field.

A Well of Yinggehai Basin was drilled in December 2010 (Figure 5), the purpose of the drilling is to confirm hydrocarbon potential and reserves of lower sand body of Dongfang 1-1 West Yinggehai Group Sec and upper sand body of Huangliu Group; to get the data of reservoir properties, reservoir fluid properties and capacity of Dongfang 1-1 West. The cover this well drilled is different from that of DFC Well and DFD Well (C well and D well in Dongfang zone). The well is located on the west side of Dongfang Diapirs, outside diapiric anticline. The drilling result revealed a set of transgressive-highstand system tract shallow mudstone caprock upper Huangliu Group, which thickness was up to $220 \mathrm{~m}$, this set of direct cover has the following characteristics: great thickness, pure mudstone, strong plasticity (poor drilling ability), higher degree of compaction, wide distribution, with overpressure (pressure coefficient for 1.5 - 1.8) (Figure 6), which showed good performance of high-

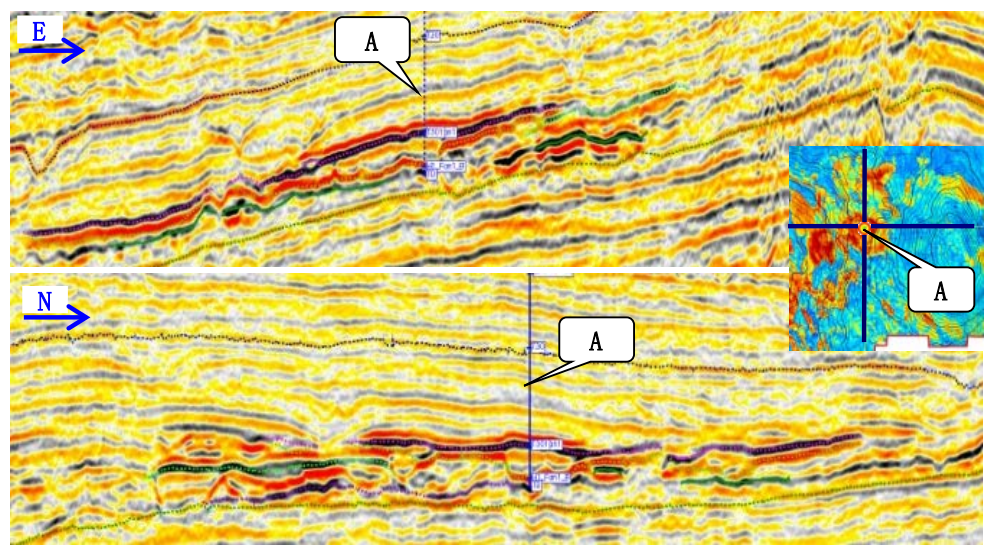

Figure 5. Typical cross section of well. 


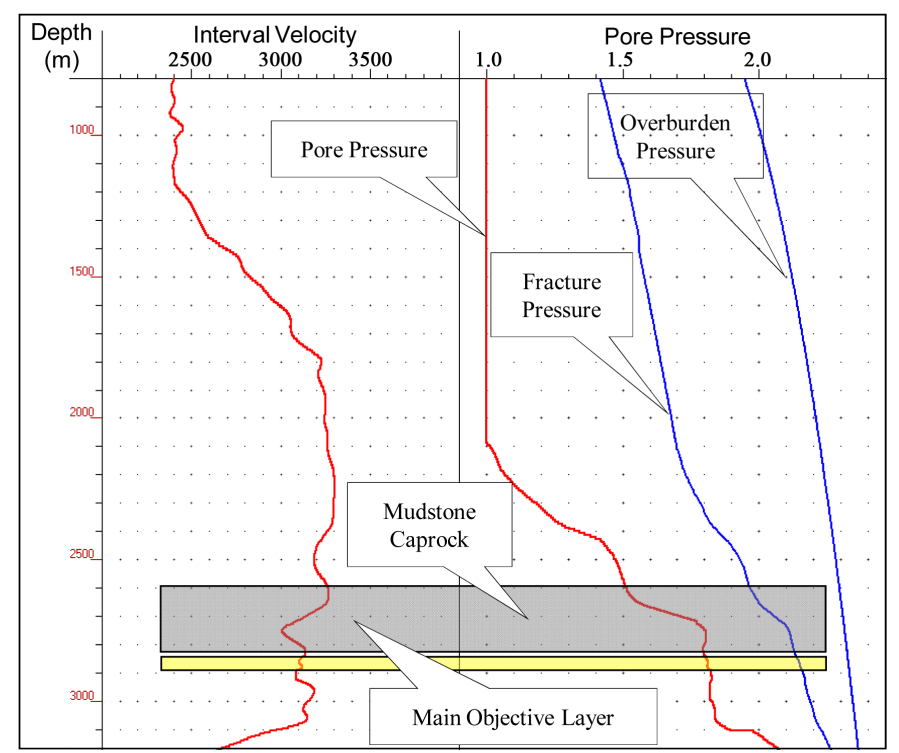

Figure 6. Pre-drilling pressure prediction map of well.

pressure sealing ability and provided an important safeguard for the formation of abnormal high pressure gas.

A Well got high-quality and high-yield airflow in high-temperature and high-pressure field of deep Huangliu Group for the first time, which revealed a new model for the formation of high-pressure gas reservoirs and broke the previous research field: 1 ) It is proved that high-quality gas reservoir can be formed in deep Overpressure Field (pressure coefficient $>1.8$ ); 2) IT is revealed that geological conditions are available to develop large reservoir in deep Huangliu Group of basin; 3) the possibility of deep lithologic trap is confirmed, which has widened the gas exploration field of basin. Research shows that Huangliu Group is an excellent strata with good deep reservoir development condition of Yinggehai Basin, moderate depth, good reservoir conditions, great reservoir potential, which has been proved by the successful of A Well.

\section{Conclusions}

Yinggehai Basin is a typical high-temperature and high-pressure basin. After years of exploration, "velocity difference method" is proved to be suitable for pre-drilled pressure prediction and drilled pressure calculation, which has high accuracy. In the process of drilling of high-temperature and high-pressure basin, security must be paid more attention. Before designing drilling well structure, the most important is pre-drilled pressure prediction. The paper started from tectonic pattern of Yinggehai Basin and single hydrocarbon structural, summarized several pressure prediction models, including center of Yinggehai Basin, edge of the basin.

Dongfang Diapir, Ledong Diapir, Yingbei Lingao and Yingdong Xiepo analyzed the relationship of velocity difference and pressure coefficient and the reason of differences among the models, which has provided basic support for the pre-drilled pressure prediction in different area of Yinggehai Basin. The success of A Well and acquirement of high-quality gas in high-temperature and high-pressure region of deep Huangliu Group has revealed a new pattern to form high-pressure gas reservoir, and eliminated the doubt that if gas reservoir can be formed under deep high-temperature and super overpressure condition, which has broken the previous research field.

\section{References}

[1] Zhang, S.-L. (2004) The Key Problem of Drilling Pressure and the Solving Method of the Prediction. Marine Geological Dynamic, 20, 122-126.

[2] Zhang, W.-H., He, S. and Guo, Q.-S. (2005) The Methods and Headway for Pressure Prediction. Progress in Geophysics, 20, 101-106.

[3] Fan, H.-H. and Zhang, C.-J. (2005) New Methods for Calculation of Pore Pressure in Complex Geologic Environment. Petroleum Drilling Techniques, 33, 40-43. 
[4] Liu, Z., Xue, X.-M., Xie, Q.-C., et al. (2006) Overpressure Characteristics in the Jiyang Depression, the Bohaiwan Basin. Modern Geology, 222-227.

[5] Wei, M.A., Chen, C., Wang, Y.J., et al. (2007) New Approach for Pore Pressure Prediction. Oil \& Gas Geology, 395400.

[6] Ai, C., Feng, F.-P. and Li, H.-W. (2007) Current Situation and Development Trend of Formation Pressure Prediction. Petroleum Geology and Engineering, 21, 71-73.

[7] Liu, Q.W., He, J.X. and Chen, G.M. (2005) Reservoir Characteristics of Deep Natural Gas in Yinggehai Basin. Natural Gas Industry, 22, 1-3.

[8] Huang, B.J., Li, X.S., Yi, P., et al. (2005) Geochemical Behaviors and Reservoiring History of Natural Gas in Ledong Gas Field in Yinggehai Basin. Oil \& Gas Geology, 26, 524-529.

[9] Hao, F.-D., Wei, H.-Z., Hua, Y., et al. (2003) Overpressure Fluid Flow and Rapid Accumulation of Natural Gas in Yinggehai Basin. Acta Petrolei Sinica, 24, 79-85. 